\title{
GH receptor isoforms and skeletal fragility in acromegaly
}

\author{
Marilda Mormando', Luigi A Nasto ${ }^{2}$, Antonio Bianchi' ${ }^{1}$, Gherardo Mazziotti ${ }^{3}$, \\ Antonella Giampietro ${ }^{1}$, Enrico Pola ${ }^{2}$, Alfredo Pontecorvi ${ }^{1}$, Andrea Giustina ${ }^{3}$ \\ and Laura De Marinis'
}

${ }^{1}$ Pituitary Unit, Department of Endocrinology and ${ }^{2}$ Division of Spine Surgery, Department of Orthopaedics and Traumatology, Catholic University School of Medicine, 'A. Gemelli' University Hospital, I.go Agostino Gemelli 8, 00168 Rome, Italy and ${ }^{3}$ Chair of Endocrinology, University of Brescia, 25125 Brescia, Italy
Correspondence should be addressed to E Pola

Email

enrico.pola@rm.unicatt.it

\begin{abstract}
Objective: Acromegaly is associated with an increased prevalence of vertebral fractures (VFs) in close relationship with GH hypersecretion. Two isoforms of the GH receptor (GHR) have been identified; the two isoforms differ or not by the expression of the protein fragment encoded by exon 3 of the GHR gene. Deletion of the exon 3 may influence the functional properties of the GHR and affect fracture risk in acromegalic patients.

Design: A cross-sectional study was designed to investigate the association between the d3-GHR isoform and the prevalence of VFs in patients with acromegaly.

Methods: In this study, 109 acromegalic patients were included (M/F, 48/61): 73 with controlled/cured acromegaly and 36 with active disease. GHR genotype was assessed in each patient. All patients were evaluated for VFs and bone mineral density at lumbar spine and hip. Serum IGF1 levels and bone metabolism markers were measured. A multivariate analysis was performed to establish risk factors for VFs in our population.

Results: d3-GHR carriers showed an increased prevalence of VFs when compared with patients expressing full-length GHR (35/55 vs $12 / 54 ; P<0.001)$. The association between $G H R$ deletion and VFs was demonstrated both in patients with active disease and in those with controlled/cured disease. Out of 35 patients who were prospectively evaluated, $13(37.1 \%)$ developed incident VFs. The incidence of VFs was significantly higher in patients for whom the GHR gene has been deleted when compared with those harboring the $f l$ gene $(P=0.04)$. In multivariate analysis, male sex (odds ratio (OR), 3.250; $P=0.041)$, IGF1 levels (OR, 1.183; $P=0.031$ ), length of active diseases (OR, 1.038; $P=0.001)$, and $d 3-G H R$ genotype (OR, 3.060; $P=0.015)$ were all confirmed as risk factors of VFs in our population.

Conclusions: This study suggests for the first time that exon 3 deletion of GHR may predispose patients with active and controlled acromegaly to a higher risk of VFs.
\end{abstract}

\section{Introduction}

Growth hormone (GH) and insulin-like growth factor 1 (IGF1) are important regulators of the bone remodeling process. Although GH may act directly on skeletal cells, most of its effects are mediated by IGF1 that exerts its action as a systemic hormone synthesized in the liver under GH stimulation or as a local growth factor synthesized in peripheral tissues (1). Circulating GH binds to a single-chain transmembrane glycoprotein receptor (GH receptor (GHR)). The GHR in its final form consists of an extracellular, a transmembrane, and an intracellular domain, whereas the GHR gene consists of nine exons encoding the receptor protein and several additional untranslated exons (2). To date, two isoforms of human GHR have been identified: a full-length (fl-GHR) isoform retaining the protein fragment encoded by exon 3 and an exon 3-deficient (d3-GHR) isoform excluding this (c) 2014 European Society of Endocrinology Printed in Great Britain
Published by Bioscientifica Ltd. 
fragment (3). Exon 3 encodes a segment in the extracellular domain of the receptor; although both the isoforms retain the capacity of binding $\mathrm{GH}$ with a high affinity, there may well be significantly functional differences between the two isoforms $(4,5)$. In fact, GH-deficient patients expressing d3-GHR isoform are known to be more responsive to $\mathrm{GH}$ replacement therapy than fl-GHR patients $(5,6,7)$. Acromegalic patients with exon 3 being deleted in the GHR gene consistently express higher serum IGF1 levels even after treatment with somatostatin analogs or pegvisomant $(8,9,10,11)$. Moreover, exon 3 deletion in acromegalic patients has been associated with a higher incidence of long-term complications of the disease, such as diabetes, osteoarthritis, and colon polyps $(12,13)$.

Over the recent past years, an expanding body of knowledge is supporting the idea that patients with acromegaly suffer from skeletal fragility and are at an increased risk for vertebral fractures (VFs). Fracture risk correlates with the activity of the disease and the presence of concomitant additional risk factors, such as hypogonadism $(14,15,16)$. Nonetheless, it is still largely unclear as to whether GHR polymorphisms are implicated in this phenomenon and have an impact on skeletal fragility in acromegaly. Recently, Wassenaar et al. (13) did not find any significant association between the deletion of $G H R$ exon 3 and VFs. However, the authors restricted their analysis to patients with longstanding controlled acromegaly. In our opinion, active acromegaly may well provide a better model to study the potential impact of $G H R$ polymorphisms on skeletal fragility. Therefore, the aim of our study is to investigate the effects of exon 3 deletion of GHR on bone metabolism, bone mineral density (BMD), and incidence of VFs in patients with active and controlled/cured acromegaly.

\section{Subjects and methods}

\section{Subjects}

A cross-sectional study was designed and a total of 109 patients consecutively treated at our Institution (Pituitary Unit of Endocrinology Department, Gemelli Hospital, Rome) were enrolled. All patients were diagnosed with acromegaly or had a previous diagnosis of acromegaly. Exclusion criteria from the study were: i) diagnosis of active neoplastic disease; ii) ongoing treatment with antiosteoporotic drugs with the exception of calcium and vitamin D supplements; iii) treatment with drugs causing osteoporosis with the exception of glucocorticoid replacement therapy in hypopituitaric patients; iv) clear history of moderate or high-energy VFs; v) history of surgical intervention on the spine; and vi) prolonged immobilization (more than 6 weeks). Out of the 109 enrolled patients, 84 had been already evaluated in previously published studies from our research group $(14,15,16)$. Both surgically treated and medically treated patients were included.

Active acromegaly was defined as the failure of suppression of $\mathrm{GH}$ plasma levels $\leq 1 \mathrm{ng} / \mathrm{ml}$ after a $75 \mathrm{~g}$ oral glucose load and fasting plasma IGF1 levels above the normal ranges for sex and age (17). Patients undergoing somatostatin analog treatment were evaluated by measurement of serum random GH and IGF1, and those undergoing pegvisomant were evaluated by serum IGF1 alone, whereas patients treated by neurosurgery alone were evaluated also by serum GH after a $75 \mathrm{~g}$ oral glucose load, according to the current guidelines (18). Acromegaly was defined as controlled if the IGF1 values were within the reference ranges for age and, in patients undergoing treatment with somatostatin analogs and after neurosurgery, random GH was below $1.0 \mathrm{ng} / \mathrm{ml}$. When the $75 \mathrm{~g}$ oral glucose load was performed, the $\mathrm{GH}$ values of $0.4 \mathrm{ng} / \mathrm{ml}$ or below were considered as expression of cured disease. Disease activity was defined as 'cured' if, after a previous treatment for acromegaly, patients had normal biochemical parameters at follow-up with no ongoing medical therapy. Patients' gonadal status was also assessed: hypogonadism was defined as absence of or irregular menstrual cycles in women and low total testosterone associated with symptoms and signs of sexual dysfunction in men. Hypogonadic patients undergoing replacement therapy with sex steroids were assumed to be eugonadal only if treatment was started at least 12 months before study entry. All patients signed an informed consent form after full explanation of the purpose and nature of all procedures used. The study was also approved by our Institutional Ethical Committee.

\section{Biochemical measurements}

All biochemical measurements were performed within 6 months of lumbar and femoral neck dual energy X-ray absorptiometry (DXA) scan and vertebral X-ray assessment. Blood samples were collected in fasting conditions. GH and IGF1 levels were measured using the Immulite 2000 immunoassay system (Siemens, Diagnostic Product Corp., Los Angeles, CA, USA). The inter-assay coefficient of variation was $5.5-6.2 \%$ for GH assay, and $6.4-11.5 \%$ for IGF1 assay; detection lower limits were 0.01 and $0.2 \mu \mathrm{g} / \mathrm{l}$ 
respectively. IGF1 levels were reported as absolute concentrations and SDS relative to normal age-adjusted adult values (normal range from -2 to +2 SDS). The formula used for SDS calculation is, as reported previously, $\left(\left(\mathrm{IGF} 1_{P}-\mathrm{IGF} 1_{\text {adj-value }}\right) / \mathrm{IGF} 1_{\text {s.D. }}\right)$, where $\mathrm{IGF} 1_{P}$ is the absolute level of IGF1 of the patient, and IGF1 $1_{\text {adj-value }}$ and IGF $1_{\text {S.D. }}$ are the average and the S.D. of the age-matched IGF1 levels in healthy patients respectively (19). Serum 25-hydroxy vitamin D was measured using a chemiluminescent assay (Liaison Instrument, DiaSorin Inc, Stillwater, MN, USA), reference intervals for the study were $<10 \mathrm{ng} / \mathrm{ml}$ for severe deficiency, $10-30 \mathrm{ng} / \mathrm{ml}$ for mild to moderate deficiency, and $31-100 \mathrm{ng} / \mathrm{ml}$ for normal status. Serum parathyroid hormone levels were also measured using an immunoenzymatic method (reference interval, $10-65 \mathrm{pg} / \mathrm{ml}$ ), osteocalcin by the ECLIA method (reference interval, $15-45 \mathrm{ng} / \mathrm{ml}$ ), and $\beta$-crosslaps ( $\beta$-CTx) by a chemiluminescent immunoassay (reference interval, $0.2-1.0 \mathrm{ng} / \mathrm{ml}$ ).

\section{Measurement of BMD and quantitative morphometrical assessment of VFs}

BMD of femoral neck and lumbar spine was measured by DXA (Lunar Prodigy 8743, GE Medical System, Madison WI, USA). Measurements were made at the time of the spinal $\mathrm{X}$-ray. BMD is expressed as absolute values and $Z$-scores using a standard Caucasian European reference population. Fractured vertebrae, defined as described below, were excluded from the lumbar BMD analysis. A quantitative morphometrical assessment of VFs in the T4-L4 region was performed using a dedicated morphometrical software (Spine-X Analyzer, ICAM Diagnostics, Milan, Italy) (20). Briefly, using a translucent digitizer and a cursor, six points were marked on the borders of each vertebral body. Anterior $(\mathrm{Ha})$, middle $(\mathrm{Hm})$, and posterior $(\mathrm{Hp})$ vertebral heights were measured and height ratios were calculated for each vertebra from $\mathrm{T} 4$ to L4; fractures were defined as mild, moderate, or severe based on a height ratio decrease of $20-25,25-40$, and more than $40 \%$ respectively (21). All VFs identified by the morphometrical scan were independently and blindly reviewed by two experienced physicians (M Mormando and L A Nasto). Moreover, a spinal deformity index (SDI) was calculated for each patient. Each VF was assigned a score according to the fracture severity (one for mild, two for moderate, and three for severe); SDI was defined as the sum of all scores in a single patient (22).

After 3 years of follow-up, 35 patients without preexisting VFs were evaluated for incident VFs. Incident VFs were defined as a decrease of $20 \%$ or more and at least
$4 \mathrm{~mm}$ in length in any of the three vertebral heights (Ha, $\mathrm{Hm}$, or Hp) compared with baseline radiograph (16).

\section{Genetic testing}

DNA was extracted from 100-200 $\mu$ l peripheral blood using the Illustra blood genomicPrep Mini Spin Kit (GE Healthcare, Little Chalfont, UK) for the detection of the GHR gene polymorphism. Polymorphisms were studied through standard PCR amplification by Eppendorf Master Mix $(2.5 \times)$ (Eppendorf, Hamburg, Germany). The following primers were used for amplification, 5'-TGTGCTGGTCTGTTGGTCTG-3', 5'-AGTCGGTTCCTGGGACGAGA- $3^{\prime}$, and $5^{\prime}$-CCTGGATTAACACTTTGCAGACTC-3' (23). The reaction was carried out with one cycle at $94{ }^{\circ} \mathrm{C}$ for $5 \mathrm{~min}$ (denaturing), 35 cycles at $94^{\circ} \mathrm{C}$ for $30 \mathrm{~s}$ (denaturing), $60^{\circ} \mathrm{C}$ for $30 \mathrm{~s}$ (annealing), $72^{\circ} \mathrm{C}$ for $60 \mathrm{~s}$ (extension), and one cycle at $72^{\circ} \mathrm{C}$ for $7 \mathrm{~min}$ (last extension). The amplification products were separated by electrophoresis on $2 \%$ agarose gel and visualized by ethidium bromide labeling. The full-length allele ( $f l-G H R$ ) is represented by a 935-bp fragment and the exon 3-deficient allele (d3-GHR) by a 532-bp fragment.

\section{Statistical analysis}

Data are expressed as mean \pm s.D., unless otherwise stated. Continuous variables were tested using the $t$-test, whereas frequencies were compared using the $\chi^{2}$-test with the Fisher correction, when appropriate. Correlation between variables was sought using Pearson's correlation coefficient. A multivariate logistic regression model was used for statistical analysis of risk factors for occurrence of VFs. Statistical significance was assumed when $P \leq 0.05$. Data were analyzed using the SPSS Software, version 17.

\section{Results}

A total of 48 men and 61 women were included in the study (mean age 47 years, $\pm 19-79$ ). Of them, 58 patients had controlled disease (nine of them received medical therapy as first-line treatment, whereas 49 were treated with somatostatin analogs or pegvisomant after unsuccessful neurosurgery) and 15 patients were cured by neurosurgery. The remaining 36 patients had active disease; of them, 31 were on medical therapy after unsuccessful neurosurgery and radiotherapy and five were waiting for surgery or refused it at the time of this study. Of the total number of patients, 61 patients were eugonadal (35 men and 26 women), 20 patients were 
hypogonadal (13 men and seven women), and the remaining 28 women were post-menopausal and were assigned to the hypogonadic group as well.

We found 54 patients (49.5\%) to be homozygous for the fl-GHR isoform and 55 patients (50.5\%) to be carriers of at least one allele of the d3-GHR isoform. A total of 18 patients were homozygous for the d3-GHR isoform. Patients were assigned to two groups: i) homozygous carriers of the WT allele ( $f l f l-G H R$, referred as $f l$ patients hereafter) and ii) homozygous or heterozygous carriers of the exon 3-deficient allele (fld3-GHR and d3d3-GHR, referred as $d 3$ patients hereafter). We decided to apply a dominant model because we did not observe any significant difference in terms of VFs between carriers of one d3 allele and carriers of two d3 alleles; we did not observe any gene-dosage effect on fractures. The two groups did not differ in sex, lumbar BMD values, serum IGF1 levels, and bone metabolism parameters (PTH, vitamin $\mathrm{D}$, osteocalcin, and $\beta$-CTx). BMD and $Z$-score of the lumbar spine were not different between $f l$ patients and $d 3$ patients even after adjusting values for gender and BMI (Table 1). A significantly positive linear correlation between IGF1-SDS levels and $\beta$-CTx was observed both in $d 3$ patients (Pearson's $R^{2}, 0.552 ; P=0.001$ ) and in $f l$ patients (Pearson's $R^{2}, 0.194 ; P=0.022$ ), whereas only a positive trend was observed between IGF1-SDSs and osteocalcin in d3 patients (Pearson's $R^{2}, 0.0433$;
$P=0.407)$. No correlation was found between IGF1-SDS and osteocalcin levels in $f l$ patients (Pearson's $R^{2}, 0.060$; $P=0.192$; Fig. 1).

Of the total number of patients, 47 (43.1\%) had at least one VF, with a total of 53 mild, 13 moderate, and eight severe fractures. The average SDI of fractured patients was 2.19 ( \pm 1.48$)$. Fractured patients did not differ from non-fractured patients with regard to age (48.49 vs 45.32 years, $P=0.213)$, lumbar $Z$-score $(-0.57$ vs -0.10 , $P=0.100)$, femoral $Z$-score $(0.153$ vs $0.280, P=0.527)$, and duration of total disease (91.43 vs 72.17 months, $P=0.151)$. Patients with fractures were more frequently male (27/47 males, $57.4 \%$ vs $21 / 62$ females, $33.8 \%$ ) $(P=0.012)$. Moreover, fractured patients showed significantly higher IGF1 levels (SDS 3.45 vs $2.10 ; P=0.022$ ), and had longer duration of active disease (52.43 vs 23.31 months; $P<0.001$ ) than non-fractured patients. PTH and vitamin $\mathrm{D}$ levels did not differ significantly between the two groups. Osteocalcin levels did not differ significantly either $(P=0.769)$, whereas $\beta$-CTx levels were higher in fractured patients although not significantly so $(0.61$ vs $0.45 \mathrm{ng} / \mathrm{ml} ; P=0.071$ ) (Table 2 ).

Prevalence of VFs was significantly higher in $d 3$ carriers than $f l$ patients (63.6 vs $22.2 \% ; P<0.001$ ) and this association was confirmed in patients with controlled/cured and active disease (Fig. 2). The mean SDI was significantly higher in fractured $d 3$ carriers $(1.24 \pm 1.44)$

Table 1 Baseline characteristics of the two populations of the study (fIfl-GHR carriers vs fld3/d3d3-GHR carriers). Values are expressed as mean \pm s.D. unless otherwise stated.

\begin{tabular}{l} 
Variables \\
\hline Age \\
Sex (M/F) \\
Length of disease \\
Total (months) \\
Active (months) \\
Disease status \\
Lumbar BMD \\
Lumbar Z-score \\
Femoral neck BMD \\
Femoral neck Z-score \\
IGF1 (SDS) \\
PTH (pg/ml) \\
Vitamin D (ng/ml) \\
Osteocalcin (ng/ml) \\
Crosslaps (ng/ml) \\
No. of fractured patients (\%) \\
No. of fractures \\
Fractures/patient \\
SDI
\end{tabular}

SDI, spinal deformity index.

\begin{tabular}{c}
\hline flfl $(n=54)$ \\
\hline $46.52( \pm 14.21)$ \\
$54(23 / 31)$ \\
\\
$83.87( \pm 68.63)$ \\
$38.79( \pm 41.40)$ \\
20 active, 28 controlled, \\
and six healed \\
$1.165( \pm 0.168)$ \\
$-1.132( \pm 1.328)$ \\
$1.036( \pm 0.212)$ \\
$0.288( \pm 0.948)$ \\
$3.13( \pm 3.35)$ \\
$51.33( \pm 26.92)$ \\
$15.80( \pm 11.03)$ \\
$22.48( \pm 12.50)$ \\
$0.57( \pm 0.41)$ \\
$12 / 54(22 \%)$ \\
mild, four moderate, \\
and six severe) \\
0.35 ( \pm 0.70$)$ \\
$0.65( \pm 1.43)$
\end{tabular}

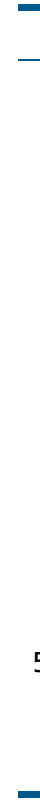

fld3-d3d3 $(n=55)$
$46.85( \pm 12.06)$
$55(25 / 30)$
$77.44( \pm 69.37)$
$33.86( \pm 36.52)$
16 active, 29 controlled,
and ten healed
$1.113( \pm 0.163)$
$-0.468( \pm 1.287)$
$0.980( \pm 0.143)$
$0.154( \pm 0.893)$
$2.65( \pm 2.97)$
$54.51( \pm 39.10)$
$15.66( \pm 11.07)$
$27.67( \pm 25.09)$
$0.62( \pm 0.41)$
$35 / 55(63 \%)$
mild, nine moderate,
and two severe)
$1.00( \pm 1.00)$
$1.24( \pm 1.44)$

\begin{tabular}{r}
$P$ value \\
\hline 0.894 \\
0.457 \\
\\
0.631 \\
0.531 \\
0.484 \\
\\
0.146 \\
0.240 \\
0.141 \\
0.503 \\
0.382 \\
0.631 \\
0.951 \\
0.322 \\
0.616 \\
$<0.001$ \\
\\
$<0.001$ \\
0.035
\end{tabular}



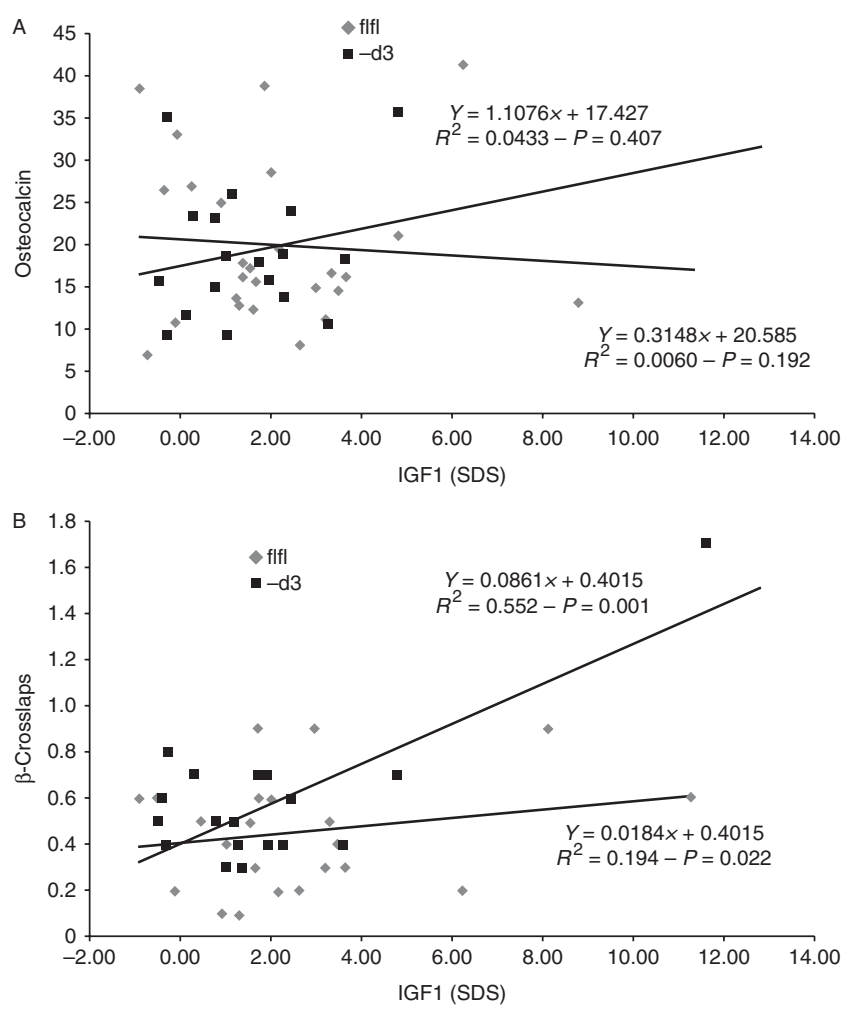

\section{Figure 1}

(A) Linear correlation between IGF1 (SDS) levels and osteocalcin levels. (B) Linear correlation between IGF1 (SDS) levels and $\beta$-crosslaps levels.

than in fractured $f l$ carriers $(0.65 \pm 1.43)(P=0.035)$. In 35 patients prospectively evaluated, 13 (37.1\%) developed incident VFs. The incidence of VFs was significantly higher in patients for whom the GHR gene has been deleted when compared with those harboring the $f l$ gene (52.6 vs $\left.18.8 \% ; \chi^{2}, 4.3 ; P=0.04\right)$.

\section{Multivariate analysis}

Variables associated with VFs were entered in a multivariate logistic regression model in order to assess the fracture risk associated with each variable. GHR isoform, IGF1 levels, length of active disease, and male sex were all significantly associated with an increased risk of VFs. Odds ratio (OR) of having a VF in patients who were carriers of one or two d3 alleles was $3.060(P=0.015)$. Each $1+\mathrm{IGF} 1-$ SDS level was associated with a 1.183 OR $(P=0.031)$, whereas length of active disease each month had $1.038 \mathrm{OR}$ $(P=0.001)$. Male sex was associated with an increased risk of VFs with an OR of $3.250(P=0.041$; Table 3$)$.

\section{Discussion}

Data from our study demonstrate for the first time, to the best of our knowledge, that the deletion of the exon 3 of GHR (d3-GHR) in at least one allele is associated with a higher prevalence of VFs in acromegalic patients. This is the first report examining the effects of GHR isoforms on bone fragility and risk of VFs in a heterogeneous population of patients (active acromegaly, controlled/ cured disease).

The d3-GHR polymorphism enhances GHR signal transduction by altering the structure of the extracellular domain of the receptor. The increased intracellular signal transduction may enhance sensitivity to GH as demonstrated by studies conducted on GH-deficient children

Table 2 Baseline characteristics of the two populations of the study (fractured patients vs patients without fractures).

\begin{tabular}{|c|c|}
\hline Variables & Fractured $(n=47)$ \\
\hline Age & $48.49( \pm 14.48)$ \\
\hline $\operatorname{Sex}(M / F)$ & $27 / 20$ \\
\hline Lumbar BMD & $1.112( \pm 0.165)$ \\
\hline Lumbar Z-score & $-0.57( \pm 1.374)$ \\
\hline Femoral BMD & $1.007( \pm 0.170)$ \\
\hline Femoral Z-score & $0.153( \pm 0.801)$ \\
\hline IGF1-SDS & $3.45( \pm 3.52)$ \\
\hline \multicolumn{2}{|l|}{ Length of disease } \\
\hline Total (months) & $91.43( \pm 77.38)$ \\
\hline Active (months) & $52.43( \pm 47.46)$ \\
\hline PTH (pg/ml) & $57.20( \pm 46.63)$ \\
\hline Vitamin D (ng/ml) & $14.97( \pm 11.39)$ \\
\hline Osteocalcin (ng/ml) & $20.61( \pm 8.96)$ \\
\hline Crosslaps (ng/ml) & $0.61( \pm 0.36)$ \\
\hline Gonadal status & 24 ipogon/23 no ipogon \\
\hline GHR polymorphism & $12 \mathrm{flfl} / 35 \mathrm{~d} 3$ \\
\hline
\end{tabular}

\begin{tabular}{|c|c|}
\hline Non-fractured $(n=62)$ & $P$ value \\
\hline $45.32( \pm 11.91)$ & 0.213 \\
\hline $21 / 41$ & 0.012 \\
\hline $1.158( \pm 0.167)$ & 0.210 \\
\hline$-0.10( \pm 1.230)$ & 0.100 \\
\hline $1.008( \pm 0.193)$ & 0.980 \\
\hline $0.280( \pm 1.017)$ & 0.527 \\
\hline $2.10( \pm 2.29)$ & 0.022 \\
\hline $72.17( \pm 60.49)$ & 0.151 \\
\hline $23.31( \pm 23.67)$ & $<0.001$ \\
\hline $49.66( \pm 17.72)$ & 0.256 \\
\hline $16.33( \pm 10.74)$ & 0.540 \\
\hline $19.82( \pm 8.96)$ & 0.769 \\
\hline $0.45( \pm 0.21)$ & 0.071 \\
\hline 24 ipogon/38 no ipogon & 0.137 \\
\hline $42 \mathrm{flfl} / 20 \mathrm{~d} 3$ & $<0.001$ \\
\hline
\end{tabular}

ipogon, hypogonadic. 

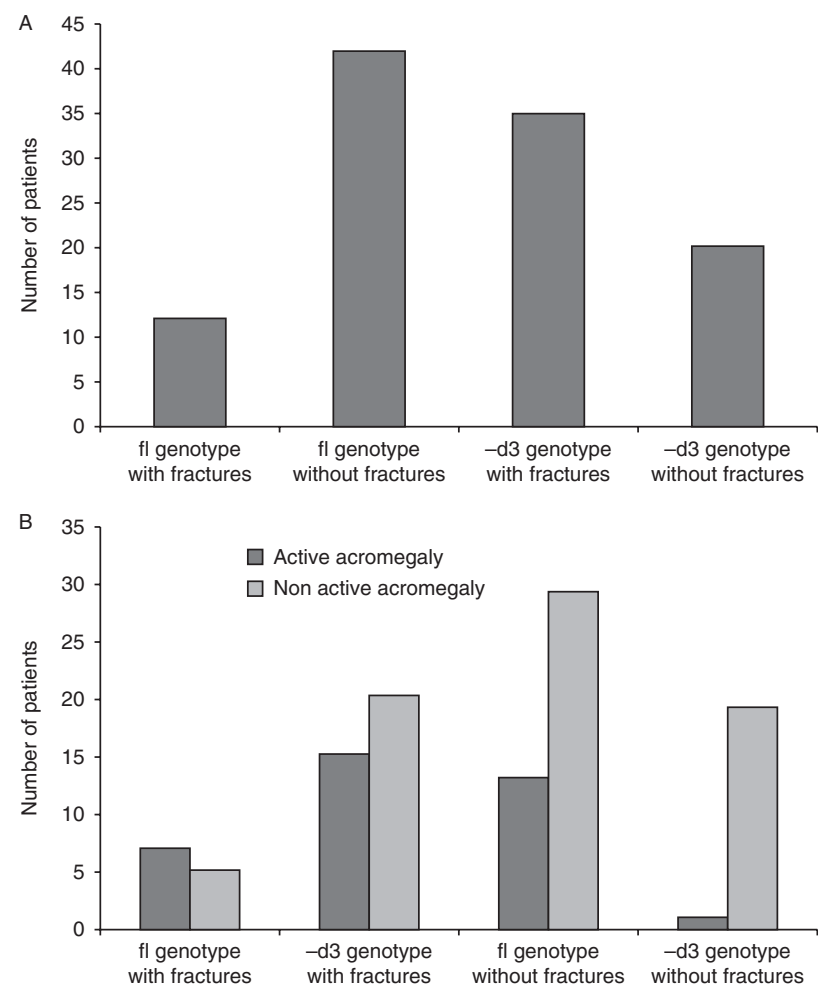

\section{Figure 2}

Both in active acromegalic and controlled disease, carriers of at least one d3 allele had a significantly increased prevalence of VFs ( $P 0.0001$ and $P 0.001)$. A, d3 genotype was associated to increased prevalence of VFs $(P<0.001) ; B$, Both in active acromegaly and controlled disease, carriers of at least one $\mathrm{d} 3$ allele had a significantly increased prevalence of VFs $(P=0.001$ and $P=0.002$ ).

treated with recombinant human GH. Patients expressing d3-GHR have an increased growth velocity and eventually they reach a higher final height $(6,7)$. On the other hand, d3-GHR polymorphism confers higher susceptibility to $\mathrm{GH}$ stimulation in acromegalic patients and may negatively affect phenotypic presentation and long-term complications of the disease. Nonetheless, the effect of d3-GHR polymorphism on GH/IGF1 levels is controversial. Mercado et al. (24) reported a significant correlation between IGF1 and GH levels only in d3-GHR carriers. Bianchi et al. (9) demonstrated that basal GH vs IGF1 relationship was concordant in $d 3$ carriers, but it became discordant (GH normal and IGF1 increased) after neurosurgery or somatostatin analog treatment, thus suggesting that small differences in GHR isoforms sensitivity exist and are possible although these differences could not be immediately evident in active acromegaly because of the elevated levels of circulating GH. At the time of our study, there were no differences observed in terms of IGF1 levels between fl-GHR and d3-GHR carriers, although we did not measure GH levels because of the confounding effect of some therapies (pegvisomant) on this assessment.

In this study, we focused our attention on bone phenotype of acromegalic patients and particularly on the prevalence of VFs. With regard to the impact of GHR isoforms on complications of acromegaly, Montefusco et al. (25) found that patients carrying at least one $\mathrm{d} 3$ allele had a lower BMI, normal glucose tolerance, and lower insulin levels 120 min after an oral glucose load than patients homozygous for $\mathrm{fl}-G H R$; these data suggest that $G H R$ polymorphism may well affect the weight and metabolic phenotype. Wassenaar et al. (13) investigated the impact of d3 deletion of GHR on BMD, osteoarthritis, and (non) VFs. The authors also studied the prevalence of other comorbidities such as adenomatous polyps, dolicocolon, and the association between anthropometric parameters, cardiovascular risk factors, and GHR isoforms. In a selected population of patients with long-term remission of acromegaly, Wassenaar et al. demonstrated that $d 3$ carriers had an increased prevalence of osteoarthritis, adenomatous polyps, and dolicocolon but anthropometric parameters, cardiovascular risk factors, BMD, and (non) VFs did not differ between $f l$ homozygous patients and $d 3$ patients.

In our population, comprising patients with active and controlled/cured acromegaly, we confirmed some of the previous results concerning BMD not significantly correlated with fractures $(14,15)$. However, in our cohort, a significant difference in terms of prevalence of VFs was observed between $f l$ homozygous patients and $d 3$ carriers. In fact, patients carrying at least one d3 allele had a significantly increased prevalence of VFs (Fig. 2). Another original observation of our study was concerned with bone metabolism markers and their association with fractures. Previous studies demonstrated that active acromegaly was associated with increased calcium and phosphate serum levels, increased calciuria and markers of bone formation, and bone resorption $(26,27,28,29,30,31)$. Bonadonna et al. (14) found that fractured acromegalic women had

Table 3 Results from a logistic regression analysis of independent variables correlating with fracture risk.

\begin{tabular}{|c|c|c|}
\hline Independent variables & OR $(95 \% \mathrm{Cl})$ & $P$ value \\
\hline Sex (male) & $3.250(1.051-10.048)$ & 0.041 \\
\hline$d 3$ genotype & $3.060(0.700-13.381)$ & 0.015 \\
\hline IGF1-SDS (per SDS) & $1.183(0.951-1.472)$ & 0.031 \\
\hline $\begin{array}{l}\text { Length of active disease } \\
\text { (per month) }\end{array}$ & $1.038(1.016-1.060)$ & 0.001 \\
\hline
\end{tabular}


higher serum bone alkaline phosphatase and urinary deoxypiridinoline and lower serum levels of vitamin D compared with non-fractured patients, but the study population was too small (36 women) to draw any real final conclusion. In our population, $\beta$-CTx (a bone catabolism marker) correlated with a higher prevalence of VFs and, although not significant $(P=0.07)$, this assessment may be helpful to estimate bone fragility in acromegalic patients. In addition, we found a positive linear correlation between IGF1 levels (increased in active disease) and $\beta$-CTx in both $f l$ and $d 3$ patients, although the correlation was stronger for $d 3$ patients (Fig. 1). Taking the stronger linear correlation between IGF1-SDS and $\beta$-CTx in $d 3$ carriers into consideration, we can hypothesize that in these patients when acromegaly is active, the increased sensitivity to GH may increase bone remodeling and consequently plasma levels of bone catabolism markers.

Our study confirmed previous cross-sectional observations in which acromegalic patients developed VFs independent of normal BMD and there were no significant differences in terms of BMD values between fractured and non-fractured patients $(14,15,32)$. For this reason, X-ray assessment is of paramount importance in establishing the real fracture risk in patients affected by acromegaly $(33,34)$ as well as in all patients affected by other forms of secondary osteoporosis (35). In accordance with previous studies $(14,15)$, fracture rate in our population was $43 \%$ and the biochemical control of acromegaly appeared effective in reducing the risk of fractures.

We also found an increased prevalence of VFs in men, which has not been previously reported in other studies $(14,15,26,32)$. In other previous cross-sectional studies, acromegalic men and only post-menopausal women were analyzed separately. Conversely, two recent studies have demonstrated a higher prevalence of VFs in acromegalic males $(36,37)$, and also in the recently published prospective study (16), the percentage of incident fractures was slightly, but not significantly, higher in males (45\%) than in females (36\%). The authors explained this finding by assuming a bone protective effect of estrogens in pre-menopausal women included in this study. Alternatively, an increased bone tissue sensitivity to GH stimulation in males may be hypothesized as already demonstrated for other clinical end-points of GH (38). However, this effect appeared to be independent of the polymorphisms of GHR.

Although the lack of sex steroids was traditionally considered as a risk factor for bone loss at lumbar spine in patients with acromegaly (39), data on association between VFs and hypogonadism have been inconclusive $(15,32,40,41)$, probably because the negative effects of hypogonadism seem to be variable related to the activity of acromegaly (16). In fact, hypogonadism was shown to be associated with the high risk of VFs in patients with controlled/cured disease but not in those with active disease (16). Consistent with these findings, in this study performed on a mixed population of acromegaly patients (i.e. with active and controlled/cured disease), we did not find a significant association between hypogonadism and VFs.

The real novelty of this work is the strong correlation found between d3-GHR isoform and high prevalence of VFs in patients with acromegaly. Interestingly, we also observed a significant correlation between d3-GHR isoform and incident VFs in a small subgroup of acromegalic patients followed up for 3 years. Notably, all these patients did not have a high prevalence of VFs at baseline and this feature provides further evidence that deletion of GHR might have been involved in the pathogenesis of skeletal fragility in acromegaly regardless of coexistent risk factors for fractures (16). Very few contrasting data are currently available on the relationship between GHR polymorphisms and osteoporosis in healthy patients. A progressive decrease in GH secretion has been hypothesized; however, recent experimental evidences have suggested that, besides the age-dependent decline of GH and IGF1 serum levels, dysregulation of GH and IGF1 action may be due to an impairment of the post-receptor signaling of GHR (42). In rodents, complete inhibition of GH action by disrupting or knocking out of the GHR gene (which resulted in GH resistance, elevated GH levels, and markedly reduced IGF1 levels) led to reduced muscle mass and BMD (43). In line with these observations, some authors reported that subjects receiving GH replacement therapy showed no significant changes in BMD $(44,45)$, probably because of other mechanisms being involved in elderly subjects affected by pituitary disease (i.e. impaired post-receptor GH signaling). The effects of GHR exon 3 isoform expression on osteoporosis has been studied in healthy patients previously. Kenth et al. (46) studied the possible influence of GHR exon 3 isoform on final adult height, quantitative ultrasound (QUS) of the heel, and BMD (spine and femoral neck) in a healthy population of 368 white women; there was no correlation between GHR exon 3 genotype and final height, QUS, and BMD. In acromegalic patients, Waassenar et al. (13) did not find a significant difference in terms of BMD and prevalence of VFs between carriers of exon 3 deletion and patients carrying the WT allele. In our population, on the other hand, which consists also of patients affected by active acromegaly, a stronger impact of GHR polymorphism on the risk of fracture due to GH excess can be expected. 
In conclusion, our study demonstrates for the first time that another important risk factor for vertebral fragility fractures in acromegalic patients does exist, i.e. the presence of $\mathrm{d} 3$ deletion of GHR gene. Genetic testing may represent an additional tool for stratification of risk of VFs in acromegalic patients and help in devising an ordered plan and adequate management in each patient.

\section{Declaration of interest}

The authors declare that there is no conflict of interest that could be perceived as prejudicing the impartiality of the research reported.

\section{Funding}

This research did not receive any specific grant from any funding agency in the public, commercial or not-for-profit sector.

\section{Author contribution statement}

$\mathrm{L}$ De Marinis designed this study and M Mormando conducted the study. M Mormando and A Giampietro collected data. L A Nasto, A Bianchi, and G Mazziotti conducted data analysis and interpretation. M Mormando drafted the manuscript. L A Nasto, A Giustina, and E Pola revised the manuscript content. A Pontecorvi, E Pola, and L De Marinis approved the final version of the manuscript. M Mormando and L De Marinis were responsible for the integrity of the data.

\section{References}

1 Giustina A, Mazziotti G \& Canalis E. Growth hormone, insulin-like growth factors, and the skeleton. Endocrine Reviews 200829 535-559. (doi:10.1210/er.2007-0036)

2 Godowski PJ, Leung DW, Meacham LR, Galgani JP, Hellmiss R, Keret R, Rotwein PS, Parks JS, Laron Z \& Wood WI. Characterization of the human growth hormone receptor gene and demonstration of a partial gene deletion in two patients with Laron-type dwarfism. PNAS 198986 8083-8087. (doi:10.1073/pnas.86.20.8083)

3 Urbanek M, MacLeod JN, Cooke NE \& Liebhaber SA. Expression of a human growth hormone (hGH) receptor isoform is predicted by tissuespecific alternative splicing of exon 3 of the hGH receptor gene transcript. Molecular Endocrinology 1992 6279-287. (doi:10.1210/mend.6.2.1569971)

4 Sobrier ML, Duquesnoy P, Duriez B, Amselem S \& Goossens M. Expression and binding properties of two isoforms of the human growth hormone receptor. FEBS Letters 1993319 16-20. (doi:10.1016/ 0014-5793(93)80028-S)

5 Dos Santos C, Essioux L, Teinturier C, Tauber M, Goffin V \& Bougnères $\mathrm{P}$. A common polymorphism of the growth hormone receptor is associated with increased responsiveness to growth hormone. Nature Genetics 200436 720-724. (doi:10.1038/ng1379)

6 Binder G, Baur F, Schweizer R \& Ranke MB. The d3-growth hormone (GH) receptor polymorphism is associated with increased responsiveness to GH in Turner syndrome and short small-for-gestational-age children. Journal of Clinical Endocrinology and Metabolism 200691 659-664. (doi:10.1210/jc.2005-1581)

7 Jorge AA, Marchisotti FG, Montenegro LR, Carvalho LR, Mendonca BB \& Arnhold IJ. Growth hormone (GH) pharmacogenetics: influence of GH receptor exon 3 retention or deletion on first-year growth response and final height in patients with severe GH deficiency. Journal of Clinical
Endocrinology and Metabolism 200691 1076-1080. (doi:10.1210/jc. 2005-2005)

8 Schmid C, Krayenbuehl PA, Bernays RL, Zwimpfer C, Maly FE \& Wiesli P. Growth hormone $(\mathrm{GH})$ receptor isoform in acromegaly: lower concentrations of GH but not insulin-like growth factor-1 in patients with a genomic deletion of exon 3 in the GH receptor gene. Clinical Chemistry 200753 1484-1488. (doi:10.1373/clinchem.2007.085712)

9 Bianchi A, Giustina A, Cimino V, Pola R, Angelini F, Pontecorvi A \& De Marinis L. Influence of growth hormone receptor $\mathrm{d} 3$ and full-length isoforms on biochemical treatment outcomes in acromegaly. Journal of Clinical Endocrinology and Metabolism 200994 2015-2022. (doi:10.1210/ jc.2008-1337)

10 Bianchi A, Mazziotti G, Tilaro L, Cimino V, Veltri F, Gaetani E, Pecorini G, Pontecorvi A, Giustina A \& De Marinis L. Growth hormone receptor polymorphism and the effects of pegvisomant in acromegaly. Pituitary 200912 196-199. (doi:10.1007/s11102-008-0157-8)

11 Kholer S, Tschopp O, Sze L, Neidert M, Bernays RL, Spanaus KS, Wiesli P $\&$ Schmid C. Monitoring for potential residual disease activity by serum insulin-like growth factor 1 and soluble Klotho in patients with acromegaly after pituitary surgery: is there an impact of the genomic deletion of exon 3 in the growth hormone receptor (d3-GHR) gene on "safe" GH cut-off values? General and Comparative Endocrinology 2013 188 282-287. (doi:10.1016/j.ygcen.2013.04.024)

12 Turgut S, Akin F, Ayada C, Topsakal S, Yerlikaya E \& Turgut G. The growth hormone receptor polymorphism in patients with acromegaly: relationship to BMI and glucose metabolism. Pituitary 201215 374-379. (doi:10.1007/s11102-011-0329-9)

13 Wassenaar MJ, Biermasz NR, Pereira AM, van der Klaauw AA, Smit JW, Roelfsema F, van der Straaten T, Cazemier M, Hommes DW, Kroon HM et al. The exon-3 deleted growth hormone receptor polymorphism predisposes to long-term complications of acromegaly. Journal of Clinical Endocrinology and Metabolism 200994 4671-4678. (doi:10.1210/ jc.2009-1172)

14 Bonadonna S, Mazziotti G, Nuzzo M, Bianchi A, Fusco A, De Marinis L \& Giustina A. Increased prevalence of radiological spinal deformities in active acromegaly: a cross-sectional study in postmenopausal women. Journal of Bone and Mineral Research 200520 1837-1844. (doi:10.1359/ JBMR.050603)

15 Mazziotti G, Bianchi A, Bonadonna S, Cimino V, Patelli I, Fusco A, Pontecorvi A, De Marinis L \& Giustina A. Prevalence of vertebral fractures in men with acromegaly. Journal of Clinical Endocrinology and Metabolism 200893 4649-4655. (doi:10.1210/jc.2008-0791)

16 Mazziotti G, Bianchi A, Porcelli T, Mormando M, Maffezzoni F, Cristiano A, Giampietro A, De Marinis L \& Giustina A. Vertebral fractures in patients with acromegaly: a 3 year prospective study. Journal of Clinical Endocrinology and Metabolism 201398 3402-3410. (doi:10.1210/jc.2013-1460)

17 Giustina A, Barkan A, Casanueva FF, Cavagnini F, Frohman L, Ho K, Veldhuis J, Wass J, Von Werder K \& Melmed S. Criteria for cure of acromegaly: a consensus statement. Journal of Clinical Endocrinology and Metabolism 200085 526-529. (doi:10.1210/jcem.85.2.6363)

18 Giustina A, Chanson P, Bronstein MD, Klibanski A, Lamberts S, Casanueva FF, Trainer P, Ghigo E, Ho K, Melmed S et al. A consensus on criteria for cure of acromegaly. Journal of Clinical Endocrinology and Metabolism 201095 3141-3148. (doi:10.1210/jc.2009-2670)

19 Boquete HR, Sobrado PG, Fideleff HL, Sequera AM, Giaccio AV, Suárez MG, Ruibal GF \& Miras M. Evaluation of diagnostic accuracy of insulin-like growth factor (IGF)-I and IGF-binding protein-3 in growth hormone-deficient children and adults using ROC plot analysis. Journal of Clinical Endocrinology and Metabolism 200388 4702-4708. (doi:10.1210/jc.2003-030412)

20 Griffith JF \& Genant HK. New advances in imaging osteoporosis and its complications. Endocrine 201242 39-51. (doi:10.1007/s12020-0129691-2)

21 Genant HK, Jergas M, Palermo L, Nevitt M, Valentin RS, Black D \& Cummings SR. Comparison of semiquantitative visual and quantitative 
morphometric assessment of prevalent and incident vertebral fractures in osteoporosis. The Study of Osteoporotic Fractures Research Group. Journal of Bone and Mineral Research 199611 984-996. (doi:10.1002/ jbmr.5650110716)

22 Crans GG, Genant HK \& Krege JH. Prognostic utility of a semiquantitative spinal deformity index. Bone 200537 175-179. (doi:10.1016/j. bone.2005.04.003)

23 Pantel J, Machinis K, Sobrier ML, Duquesnoy P, Goossens M \& Amselem S. Species-specific alternative splice mimicry at the growth hormone receptor locus revealed by the lineage of retroelements during primate evolution. Journal of Biological Chemistry 2000275 18664-18669. (doi:10.1074/jbc.M001615200)

24 Mercado M, González B, Sandoval C, Esquenazi Y, Mier F, Vargas G, de los Monteros AL \& Sosa E. Clinical and biochemical impact of the $\mathrm{d} 3$ growth hormone receptor genotype in acromegaly. Journal of Clinical Endocrinology and Metabolism 200893 3411-3415. (doi:10.1210/jc. 2008-0391)

25 Montefusco L, Filopanti M, Ronchi CL, Olgiati L, La-Porta C, Losa M, Epaminonda P, Coletti F, Beck-Peccoz P, Spada A et al. d3-Growth hormone receptor polymorphism in acromegaly: effects on metabolic phenotype. Clinical Endocrinology 201072 661-667. (doi:10.1111/j. 1365-2265.2009.03703.x)

26 Padova G, Borzi G, Incorvaia L, Siciliano G, Migliorino V, Vetri M \& Tita P. Prevalence of osteoporosis and vertebral fractures in acromegalic patients. Clinical Cases in Mineral and Bone Metabolism 20118 37-43.

27 Halse J \& Haugen HN. Calcium and phosphate metabolism in acromegaly. Acta Endocrinologica 198094 459-467.

28 Marazuela M, Astigarraga B, Tabuenca MJ, Estrada J, Marin F \& Lucas T. Serum bone Gla protein as a marker of bone turnover in acromegaly. Calcified Tissue International 199352 419-421. (doi:10.1007/ BF00571329)

29 De la Piedra C, Larrañaga J, Castro N, Horcajada C, Rapado A, Herrera Pombo JL \& Carbó E. Correlation among plasma osteocalcin, growth hormone, and somatomedin C in acromegaly. Calcified Tissue International 198843 44-45. (doi:10.1007/BF02555167)

30 Ezzat S, Melmed S, Endres D, Eyre DR \& Singer FR. Biochemical assessment of bone formation and resorption in acromegaly. Journal of Clinical Endocrinology and Metabolism 199376 1452-1457. (doi:10.1210/jcem76.6.8501150)

31 Ueland T, Fougner SL, Godang K, Schreiner T \& Bollerslev V. Serum Gh and IGF1 are significant determinants of bone turn over but not bone mineral density in active acromegaly: a prospective study of more than 70 consecutive patients. European Journal of Endocrinology 2006155 709-715. (doi:10.1530/eje.1.02285)

32 Wassenaar MJ, Biermasz NR, Hamdy NA, Zillikens MC, van Meurs JB, Rivadeneira F, Hofman A, Uitterlinden AG, Stokkel MP, Roelfsema F et al. High prevalence of vertebral fractures despite normal bone mineral density in patients with long-term controlled acromegaly. European Journal of Endocrinology 2011 164 475-483. (doi:10.1530/EJE-10-1005)

33 Mazziotti G, Gola M, Bianchi A, Porcelli T, Giampietro A, Cimino V, Doga M, Gazzaruso C, De Marinis L \& Giustina A. Influence of diabetes mellitus on vertebral fractures in men with acromegaly. Endocrine 2011 40 102-108. (doi:10.1007/s12020-011-9486-x)

34 Melmed S, Casanueva FF, Klibanski A, Bronstein MD, Chanson P, Lamberts SW, Strasburger CJ, Wass JA \& Giustina A. A consensus on the diagnosis and treatment of acromegaly complications. Pituitary 2013 16 294-302. (doi:10.1007/s11102-012-0420-x)

35 Mazziotti G, Bilezikian J, Canalis E, Cocchi D \& Giustina A. New under standing and treatments for osteoporosis. Endocrine 201241 58-69. (doi:10.1007/s12020-011-9570-2)

36 Brzana J, Yedinak CG, Hameed N \& Fleseriu M. FRAX score in acromegaly: does it tell the whole story? Clinical Endocrinology 201480 614-616. (doi:10.1111/cen.12262)

37 Madeira M, Neto LV, de Paula Paranhos Neto F, Barbosa Lima IC, Carvalho de Mendonça LM, Gadelha MR \& Fleiuss de Farias ML. Acromegaly has a negative influence on trabecular bone, but not on cortical bone, as assessed by high-resolution peripheral quantitative computed tomography. Journal of Clinical Endocrinology and Metabolism 201398 1734-1741. (doi:10.1210/jc.2012-4073)

38 Gola M, Bonadonna S, Doga M \& Giustina A. Clinical review: Growth hormone and cardiovascular risk factor. Journal of Clinical Endocrinology and Metabolism 200590 1864-1870. (doi:10.1210/jc.2004-0545)

39 Diamond T, Nery L \& Posen S. Spinal and peripheral bone mineral densities in acromegaly: the effects of excess growth hormone and hypogonadism. Annals of Internal Medicine 1989111 567-573. (doi:10.7326/0003-4819-111-7-567)

40 Battista C, Chiodini I, Muscarella S, Guglielmi G, Mascia ML, Carnevale V \& Scillitani A. Spinal volumetric trabecular bone mass in acromegalic patients: a longitudinal study. Clinical Endocrinology 2009 70 378-382. (doi:10.1111/j.1365-2265.2008.03322.x)

41 Madeira M, Neto LV, de Lima GA, Moreira RO, de Mendonça LM, Gadelha MR \& Farias ML. Effects of GH-IGF-I excess and gonadal status on bone mineral density and body composition in patients with acromegaly. Osteoporosis International 201021 2019-2025. (doi:10. 1007/s00198-009-1165-x)

42 Perrini S, Laviola L, Carreira MC, Cignarelli A, Natalicchio A \& Giorgino F. The GH/IGF1 axis and signaling pathway in the muscle and bone: mechanisms underlying age-related skeletal muscle wasting and osteoporosis. Journal of Endocrinology 2010205 201-210. (doi:10.1677/ JOE-09-0431)

43 Berryman DE, Christiansen JS, Johannsson G, Thorner MO \& Kopchick JJ. Role of the GH/IGF1 axis in lifespan and healthspan: lessons from animal models. Growth Hormone \& IGF Research $2008 \mathbf{1 8}$ 455-471. (doi:10.1016/j.ghir.2008.05.005)

44 Fernholm R, Bramnert M, Hagg E, Hilding A, Baylink DJ, Mohan S \& Thorén M. Growth hormone replacement therapy improves body composition and increased bone metabolism in elderly patients with pituitary disease. Journal of Clinical Endocrinology and Metabolism 2000 155 4104-4112. (doi:10.1210/jcem85.11.6949)

45 Hoffman AR, Kuntze JE, Baptista J, Baum HB, Baumann GP, Biller BM, Clark RV, Cook D, Inzucchi SE \& Kleinberg D. Growth hormone (GH) replacement therapy in adult-onset GH deficiency. Effects on body composition in men and women in a double-blind, randomized, placebo-controlled trial. Journal of Clinical Endocrinology and Metabolism 200489 2048-2056. (doi:10.1210/jc.2003-030346)

46 Kenth G, Shao Z, Cole DE \& Goodyer CG. Relationship of the human growth hormone receptor exon 3 genotype with final adult height and bone mineral density. Journal of Clinical Endocrinology and Metabolism 200792 725-728. (doi:10.1210/jc.2006-1695)

Received 24 December 2013

Revised version received 21 May 2014

Accepted 27 May 2014 